\title{
Redes sociales, historia y memoria digital de la represión de mujeres en el Franquismo*
}

Ángeles Egido

UNED

megido@geo.uned.es

Matilde Eiroa

\section{Universidad Carlos III de Madrid}

meiroa@hum.uc3m.es

\section{Fecha recepción 18.04.2017 / Fecha aceptación 26.05.2017}

\section{Resumen}

En los últimos años se ha avanzado notablemente en el estudio cuantitativo y especialmente cualitativo de la represión de las mujeres durante el franquismo. Se han publicado numerosos testimonios, investigaciones rigurosas e incluso novelas, películas y documentales, a los que hay que añadir actualmente el entorno digital. En este marco, este trabajo plantea un estudio que confronta el estado

\begin{abstract}
In recent years has advanced greatly in qualitative and quantitative studies about women repression during the Franco regime. In addition to the publication of several testimonies, there are rigorous research on the Francoist prisons for women, and novels, films and documentaries. Along with these new scenarios of diffusion, the digital environment currently sets a field where also express and
\end{abstract}

\footnotetext{
* Esta investigación se enmarca en los resultados del Proyecto Historia y Memoria Histórica on line. Retos $y$ oportunidades para el conocimiento del pasado en Internet, ref. HAR-2015-63582-P MINECO/FEDER. En línea en: http://uc3m.libguides.com/hismedi [Consulta: 10.05.2017]. Las direcciones url que se citan han sido comprobadas de nuevo a fecha 3 de octubre de 2017.
} 
Miscelánea | Redes sociales, historia y memoria digital de la represión de mujeres en el Franquismo

de la cuestión en la historiografía con su presencia en las plataformas sociales a fin de comprobar el tratamiento que se le confiere en el contexto de las expresiones digitales de la represión franquista.

\section{Palabras clave}

Represión de mujeres, represión franquista, historia digital, historia pública digital, redes de relatos. disseminate content of this phenomenon of our most traumatic past. Within this framework, this paper proposes a comparative perspective among the state of arts with the presence of women prosecution in social platforms in order to verify the treatment conferred in the context of digital expressions of the Francoist repression.

\section{Key words}

women repression, Franco's repression, digital history, digital public history, network stories. 
LA INVESTIGACIÓN SOBRE LA REPRESIÓN DE LAS MUJERES en el franquismo abarca hoy día una multitud de aspectos involucrados en la misma, y es especialmente abundante en el periodo inicial denominado habitualmente "primer franquismo», entendiendo como tal los años cuarenta y cincuenta. En poco más de una década, los estudios sobre este tema y periodo han avanzado considerablemente ofreciendo un variado elenco de castigos infringidos a las mujeres por su condición de género y sus relaciones con familiares masculinos.

En las páginas que siguen mostramos un recorrido por el estado de la cuestión y un análisis de su plasmación en las plataformas sociales. El objetivo que se plantea es confrontar la producción historiográfica con la presencia de la represión de género en el denominado «archivo infinito» ${ }^{1}$, adelantando que la copiosa producción historiográfica en modo alguno corresponde con la huella de la misma en la Red. El enfoque descriptivo adoptado para el texto se ha considerado un primer paso necesario para revelar las evidencias existentes, si bien se acompaña de una interpretación de las mismas y de una ordenación temática y cualitativa.

Los trabajos de investigación que se centran en Internet como objeto de estudio deben asumir algunas limitaciones, como la renuncia a la exhaustividad, el carácter exploratorio de los resultados o la aceptación del hecho de que no se pueden dar por finalizados, aunque estas restricciones también se encuentran en las investigaciones con fuentes analógicas ${ }^{2}$. La historia digital construida con fuentes nacidas digitales se enfrenta, además, a un problema metodológico vinculado a la obligación de aprehender técnicas afines a otras ciencias sociales y al manejo de nuevas tecnologías nada fáciles para la formación recibida por los historiadores. Sin embargo, bajo este paraguas teórico y metodológico hemos considerado de interés académico y social abordar el estudio de las huellas que la sociedad digital está dejando sobre una cuestión tan relevante y escasamente visualizada como es la persecución y coerción de mujeres en los años centrales del siglo XX.

1. Sobre este concepto véase J.A. Melo Flórez, "Historia digital: la memoria en el archivo infinito", Historia Critica, 43, enero-abril 2011, 82-103.

2. A. Pons, "La historia maleable. A propósito de Internet", Hispania. Revista Española de Historia, LXVI, 222, 2006, 109-130. S. Brown et al., "Published yet never done: the tension between projection and completion in Digital Humanities research", Digital Humanities Quaterly, 3, 2, 2003. En línea en: http:// www.digitalhumanities.org/dhq/vol/3/2/000040/000040.html. [Consulta: 10.02.2017]. Z. Papacharissi, "The virtual sphere. The internet as a public sphere", New Media \& society, 4, 1, 2002, 9-27. R. Minuti, "Internet e il mestiere di storico. Riflessioni sulle incertezze di una mutazione", Cromohs, 6, 2001, 1-75. 


\section{Experiencias carcelarias}

El primer aspecto que se abordó sobre la represión de las mujeres, como es bien conocido, fue la experiencia carcelaria en la inmediata posguerra. Una iniciativa que partió de las propias presas, conscientes de la importancia de publicar sus testimonios. La primera que lo hizo fue Mercedes Núñez $(1967)^{3}$. Poco más de una década después apareció la primera edición en España del libro de Carlota $\mathrm{O}^{\prime} \mathrm{Neill}^{4}$, y el testimonio novelado de Juana Doña ${ }^{5}$. A principios de los ochenta se publicó el testimonio de Soledad Real, recogido por Consuelo García, y el de Ángeles Malonda ${ }^{6}$. Pero sobre todo hay que destacar los tres libros de Tomasa Cuevas, sin duda el mayor recopilatorio (más de 300 testimonios) de la experiencia femenina en las cárceles de posguerra. Fue una iniciativa personal, sin apoyo económico, que la llevó a recorrer toda España en busca de sus compañeras de prisión y que, publicados todavía en los inicios de la Transición, pasaron casi desapercibidos ${ }^{7}$. Habría que esperar a 2004, para que alcanzaran la repercusión que merecían ${ }^{8}$. En esta década se publicaron también otros testimonios sobre las cárceles de posguerra. Entre ellos, los de Lola Canales (2007), y poco después los de Dolores Botey (2011) o Nieves Torres (2012) .

Estas publicaciones testimoniales despertaron el interés del mundo académico, alentando investigaciones que dieron sus mejores frutos a finales de los años noventa y, sobre todo, en la década de los 2000, con la excepción del estudio pionero de Giuliana Di Febo que ya recogió en 1976 los primeros testimonios de mujeres en las cárceles franquistas ${ }^{10}$. El primer análisis riguroso de estas prisiones, alentado por Antonio Nadal que en 1980 había publicado su estudio sobre los experimentos de Vallejo Nágera con las presas de Málaga ${ }^{11}$, concluyó en 1994 con el primer libro sobre la cárcel de mujeres de esta ciudad ${ }^{12}$. El nuevo milenio trajo publicaciones de notable impacto. La primera fue la de Ricard Vinyes ${ }^{13}$, seguida por una primera aproximación de David Ginard a la prisión de mujeres de Palma, tristemente famosa porque allí se suicidó

3. M. Núñez, Cárcel de Ventas, París, 1967.

4. C. O'Neill, Una mujer en la guerra de España, $1^{a}$ ed., Madrid, 1979.

5. J. Doña, Desde la noche y la niebla (mujeres en las cárceles franquistas), Madrid, 1978.

6. C. García, Las cárceles de Soledad Real: una vida, Madrid, 1982; Á. Malonda, Aquello sucedió así, Madrid, 1983.

7. T. Cuevas Gutiérrez, Mujeres en las cárceles franquistas, $1^{\text {a }}$ ed., Madrid, 1982; Cárcel de mujeres, (Ventas, Segovia, Les Corts), $1^{\text {a }}$ ed., Barcelona, 1985 y Mujeres de la resistencia, $1^{\text {a }}$ ed., Barcelona, 1986.

8. T. Cuevas Gutiérrez, Testimonios de mujeres en las cárceles franquistas, Huesca, 2004.

9. L. Canales, Alias Lola: historia de las últimas presas politicas de la cárcel de Ventas, Madrid, 2007; D. Botey Alonso, Mis memorias. 10 años, 3 meses y 120 horas de prisión, $1^{a}$ ed., Palma de Mallorca, 2011; Á. Egido León, "Condenada a muerte: Nieves Torres, 16 años en las cárceles de Franco", en C. Marcos y R. Serrano, R. (Eds.), Mujer y política en la España contemporánea (1868-1936), Valladolid, 2012, 223-242.

10. G. Di Febo, Resistencia y movimiento de mujeres en España 1936-1976, Barcelona, 1976.

11. A. Nadal Sánchez, "Experiencias psíquicas sobre mujeres marxistas malagueñas. Málaga, 1939", en Las mujeres y la Guerra Civil Española. III Jornadas de estudios monográficos, Salamanca, 1980, 340-350.

12. E. Barranquero Texeira, M. Eiroa San Francisco y P. Navarro Jiménez, Mujer, cárcel, franquismo. La Prisión Provincial de Málaga (1937-1945), Málaga, 1994.

13. R. Vinyes, Irredentas: Las presas politicas y sus hijos en las cárceles franquistas, Madrid, 2002. 
oficialmente una de las presas emblemáticas del franquismo: Matilde Landa ${ }^{14}$, y por el libro de Fernando Hernández Holgado sobre la cárcel de Ventas ${ }^{15}$, que precedió en ocho años a su tesis doctoral (defendida en 2011) sobre Ventas y Les Corts. También hay que citar los estudios de Carme Molinero (1998) ${ }^{16}$ o Montse Duch (1999), que se ocuparon muy tempranamente de la represión de posguerra desde una perspectiva de género ${ }^{17}$.

Este interés por las prisiones de mujeres en la posguerra culminaría con la exposición Presas de Franco y la publicación de su catálogo en $2007^{18}$, y con una obra de conjunto, hasta ahora la más completa, que recoge lo que sabemos hasta el momento sobre esta cuestión, que salió primero como número monográfico doble de la revista Studia Histórica. Historia Contemporánea (Salamanca, 2011) ${ }^{19}$ y que se ha difundido como libro, revisado y actualizado, con el título: Cárceles de mujeres. La prisión femenina en la posguerra ${ }^{20}$. Además, contamos con varias monografías sobre cárceles de mujeres: la de Iván Heredia sobre la cárcel de Torrero (2005); Subirats y Poy sobre Les Oblates (2006); en 2014 Rosa M. Aragüés publicó su estudio de la cárcel de Predicadores de Zaragoza y en 2016 apareció otro sobre las presas de la cárcel de Picassent (Valencia) ${ }^{21}$.

Tanto la obra de Vinyes, como esta última sobre Predicadores destapan un tema adyacente que en los últimos años ha tenido también gran repercusión mediática y que solo se da en las cárceles de mujeres. Nos referimos a la presencia de niños, que eran encarcelados junto con sus madres y que solo podían permanecer en la prisión hasta los tres años. Después les eran arrebatados y condenados, en la práctica, a un destino incierto: ingresar en instituciones benéficas o ser adoptados por familias afines al régimen. Borrar su origen biológico era sen-

14. D. Ginard i Féron, "Matilde Landa i la presó de les dones de Palma”, en J. Sobrequés, C. Molinero y M. Sala (Eds.), Congreso: Los campos de concentración y el mundo penitenciario en España durante la guerra civil y el franquismo, Barcelona, 2003, 636-646.

15. F. Hernández Holgado, Mujeres encarceladas. La prisión de Ventas: de la República al franquismo, 1931-1941, Madrid, 2003.

16. C. Molinero, "Mujer, franquismo, fascismo. La clausura forzada en un "mundo pequeño", Historia Social, 30, 1998, 97-117. Véase también C. Molinero (Ed.), "Dossier: Mujer, represión y antifranquismo", Historia del Presente, 4, 2004.

17. M. Duch Plana, "Supervivència i repressió a la postguerra: una perspective de gènere", en AA.VV. Tiempos de silencio. Actas del IV Encuentro de Investigadores del Franquismo, Valencia, 17-19 de noviembre de 1999, 28-33.

18. S. Gálvez Biesca y F. Hernández Holgado (Eds.), Presas de Franco: catálogo de la exposición, Madrid, 2007.

19. Á. Egido León (Ed.), “Cárceles de mujeres. Las prisiones franquistas para mujeres (y para sus hijos) en la guerra y en la posguerra”, Número monográfico (doble) de Studia Historica. Historia Contemporánea, $29,2011$.

20. Á. Egido León (Ed.), Cárceles de mujeres. La prisión femenina en la posguerra, Madrid, 2017.

21. I. Heredia Urzáiz, Historia de la Cárcel de Torrero (1928-1939): delitos políticos y orden social, Zaragoza, 2005; J. Subirats Piñana y P. Poy Franco, Les Oblates 1939-1941: presó de dones a Tarragona, Valls, 2006; R.M. Aragüés Estragüés, Las rojas y sus hijos, víctimas de la legislación franquista. El caso de la cárcel de Predicadores (1939-1945), Madrid, 2014 y A. Simó Rosaleny y R. Camil Torres Fabra, La violència política contra les dones (1936-1953). El cas de la privació de llibertat en la provincia de València, Valencia, 2016. 
cillo porque en los registros carcelarios o bien no se les inscribía, o bien se hacía simplemente con su nombre de pila. Este asunto, que está en el origen del problema actual en torno a los niños robados del franquismo, saltó a la luz pública en 2002 con un documental que se emitió por la televisión catalana y que se resumió en un libro de Vinyes, Armengou y Belis ${ }^{22}$. Un asunto difícil de rastrear, por la escasez de fuentes, aunque existen estudios sobre las instituciones franquistas que se ocuparon de ellos. Destacamos, por ejemplo, los trabajos de Ángela Cenarro $^{23}$ y también un análisis del tema, desde el punto de vista jurídico ${ }^{24}$.

Los testimonios de las presas de Franco y los estudios de cárceles de mujeres se complementan con las biografías. Tanto Vinyes como Ginard o Hernández Holgado han dedicado artículos y libros a mujeres emblemáticas de la posguerra. Entre ellas hay que destacar las de Mónica Carabias y Carlos Fonseca sobre Rosario Sánchez Mora (2001 y 2006), la de Hernández Holgado sobre Soledad Real (2001), la de Vinyes sobre María Salvo (2004) y las de Ginard sobre Matilde Landa (2005) y Aurora Picornell, recién publicada. Cada una de ellas recoge una historia de vida de gran impacto emotivo y de gran valor historiográfico ${ }^{25}$.

Finalmente hay que mencionar algunas obras literarias, y varios documentales. En cuanto a las primeras se encuentra la novela de notable éxito de Dulce Chacón La voz dormi$d a(2002)^{26}$, seguida por dos obras de ficción sobre uno de los sucesos más desgraciados que ocurrieron en la cárcel de Ventas: el fusilamiento las Trece Rosas, recogidos en dos libros: el de Jesús Ferrero (2003) y el de Carlos Fonseca $(2004)^{27}$. En este último se apoyó la película Las Trece Rosas de Emilio Martínez Lázaro (2007), que tuvo el mérito de llamar la atención sobre el suceso, aunque no sea muy fiel a la realidad y se caracteriza por cierta frivolidad ante un tema de tan trágicas consecuencias. Más fiel a lo sucedido en las cárceles de mujeres en la posguerra es la película de Benito Zambrano, La voz dormida, basada en la novela homónima, y estrenada en 2011. También es necesario mencionar el libro de Alicia Ramos que estudia, desde el punto de vista literario, la obra de Chacón y los testimonios de las presas $(2012)^{28}$.

En todas estas obras se han abordado aspectos como la identidad de las represaliadas, los tipos de represión ejercida contra ellas, la violencia diferenciadora con respecto a

22. R. Vinyes, M. Armengou y R. Belis, Los niños perdidos del franquismo, Barcelona, 2002.

23. Á. Cenarro, Los niños del auxilio social, Madrid, 2009 y La sonrisa de Falange: Auxilio Social en la guerra y en la posguerra, Barcelona, 2006.

24. C. Yagüe Olmos, Madres en prisión. Historia de las Cárceles de Mujeres a través de su vertiente maternal, Granada, 2006.

25. M. Carabias Álvaro, Rosario Sánchez Mora, Madrid, 2001; C. Fonseca, Rosario Dinamitera: una mujer en el frente, Madrid, 2006; F. Hernández Holgado, Soledad Real, Madrid, 2001; R. Vinyes, El daño y la memoria. Las prisiones de Maria Salvo, Barcelona, 2004; D. Ginard i Féron, Matilde Landa. De la Institución Libre de Enseñanza a las prisiones franquistas, Barcelona, 2005 y Aurora Picornell (1912-1937), Palma de Mallorca, 2016.

26. D. Chacón, La voz dormida, Madrid, 2002.

27. J. Ferrero, Las trece rosas, Madrid, 2003 y C. Fonseca, Trece rosas rojas. La historia más conmovedora de la guerra civil, Madrid, 2004.

28. A. Ramos, Memoria de las presas de Franco, Madrid, 2012. 
los hombres y el fenómeno carcelario femenino, que tiene unas connotaciones específicas puestas especialmente de manifiesto en el monográfico, ya citado, de Studia Histórica. Entre dichas connotaciones figuran, entre otras, la presencia de lactantes y niños, el hecho de que las mujeres no salieran a trabajar fuera de la cárcel como lo hacían los hombres; el tipo de trabajo que hacían dentro de ella; la diferente incidencia de la redención de penas, aunque teóricamente la legislación era la misma; su situación más precaria, porque a las puertas de las prisiones de mujeres no había hombres haciendo cola con comida complementaria o ropa, lo que las dejaba más desprotegidas a la hora de recibir ayuda del exterior; o la obligada convivencia con las prostitutas, que les provocaban una doble reacción: el miedo al contagio de posibles enfermedades y la tendencia al proselitismo. En cierto sentido, este tema se aborda implícitamente -en cuanto a su relación con las llamadas piculinas y, sobre todo, con las quincenarias que convivían con las presas políticas en las mismas prisiones- en obras dedicadas a la prostitución, como la de Assumpta Roura y Mirta Núñez ${ }^{29}$. También se han tratado aspectos adyacentes como el papel de las mujeres de los presos, estudiado por Irene Abad o la correspondencia carcelaria ${ }^{30}$.

\section{Fusiladas, desaparecidas y otras modalidades de la represión de género}

Además de la experiencia carcelaria hay que contemplar otros aspectos de la represión de género en la posguerra, porque las mujeres fueron también ejecutadas, condenadas a muerte, enterradas en fosas comunes, depuradas, exiliadas y sometidas a múltiples formas de exclusión social.

En relación con las desaparecidas, es decir, las enterradas en fosas comunes, su número es imposible de determinar. Lo único que sabemos es que casi siempre que se exhuma una fosa aparecen en ella cadáveres de mujeres asesinadas, a veces junto a sus hijos de corta edad o con ellos en el vientre. Para este aspecto es importante la Red, como veremos más adelante, porque estos acontecimientos generan bastante impacto mediático y social y suelen registrarse en la prensa local o en los foros de asociaciones y colectivos. Antes teníamos alguna constancia historiográfica en obras de conjunto que los recogían, como la de Antonio Ontañón (2003) sobre las fosas del cementerio civil de Santander ${ }^{31}$, o recientemente el libro coordinado por Miguel Ángel Blanco $(2014)^{32}$.

29. A. Roura, Mujeres para después de una guerra. Una moral hipócrita del franquismo, Barcelona, 1998; M. Núñez Díaz-Balart, Mujeres caídas. Prostitutas legales y clandestinas en el franquismo, Madrid, 2003.

30. I. Abad Buil, En las puertas de la prisión, Barcelona, 2012; Carmen Gómez Ruiz y Luis Campos Osaba. Cárcel de Amor. Una historia real en la dictadura franquista. Documentación, Introducción y Estudio Preliminar de E. Lemus, Sevilla, 2005; V. Sierra, Cartas presas. La correspondencia carcelaria en la Guerra Civil y en el franquismo, Madrid, 2016.

31. A. Ontañón, Rescatados del olvido. Fosas comunes del cementerio civil de Santander, Santander, 2003.

32. M.A. Blanco (Ed.), Lidiando con el pasado, represión y memoria de la guerra civil y el franquismo, Granada, 2014. 
En relación con los fusilamientos de mujeres, al margen del caso de las Trece Rosas, solo hay dos estudios que abordan la cuantificación: el de Mirta Núñez y Antonio Rojas Friend sobre el cementerio de la Almudena (1997), y otro más reciente (2014) de Manuel García Muñoz, de carácter más divulgativo, que proporciona la cifra ya en el título: Ochenta mujeres. Las mujeres fusiladas en el Madrid de la posguerra ${ }^{33}$. Un caso particular, que demuestra la injusticia de una de estas ejecuciones, es el de María «La Jabalina» analizado por Manuel Girona Rubio en $2007^{34}$, y pronto dispondremos de cifras sobre mujeres extremeñas, que ha estimado Julián Chaves en un libro colectivo, coordinado por Ángeles Egido y Jorge Montes de próxima aparición.

Sobre las condenadas a muerte cuyas penas no fueron ejecutadas, todavía solo existe un estudio publicado por Ángeles Egido en 2009, y un capítulo incluido en un libro colectivo que coordinó Julio Aróstegui, Franco. La represión como sistema, en el que esta autora y Matilde Eiroa trataban este mismo asunto comparando hombres y mujeres ${ }^{35}$.

En cuanto a la depuración de mujeres de sus puestos de trabajo, contamos con la investigación de Juan Carlos Bordes sobre las funcionarias de correos (2001), de Fernández Holgado sobre las funcionarias de prisiones $(2005)^{36}$, o de las maestras ${ }^{37}$, y estudios recientes sobre la depuración de las matronas de Madrid tras la guerra civil y la represión sufrida por este colectivo ${ }^{38}$.

Los estudios de ámbito regional no olvidan incluir a las mujeres, y permiten abordar las características diferenciadoras, derivadas de la propia evolución de la guerra y de los ámbitos geográficos en que se producen. Podemos citar los primeros de Ors Montenegro para Alicante (1995), Ortiz Heras para Albacete (1996), Barrado Gracia para Teruel (1999), o

33. M. Núñez Díaz-Balart y A. Rojas Friend, Consejo de Guerra. Los fusilamientos en el Madrid de la posguerra (1939-1945), Madrid, 1997; M. García Muñoz, Ochenta mujeres. Las mujeres fusiladas en el Madrid de la posguerra, Madrid, 2014.

34. M. Girona Rubio, Una miliciana en la Columna de Hierro, María "La Jabalina”, Valencia, 2007.

35. Á. Egido León, El perdón de Franco. La represión de las mujeres en el Madrid de la posguerra, Madrid, 2009 y “Mujeres en las cárceles de Franco", en A. Mateos y Á. Herrerín (Eds.), La España del Presente. De la Dictadura a la Democracia, Madrid, 2006, 11-24; M. Eiroa y Á. Egido, "Los confusos caminos del perdón: de la pena de muerte a la conmutación”, en J. Aróstegui (Coord.), Franco: la represión como sistema, Madrid, 2012, 317-364.

36. J.C. Bordes Muñoz, "La depuración franquista de las funcionarias de correos (1936-1975)”, Historia y Comunicación Social, 6, 2001, 239-264; F. Hernández Holgado, "Carceleras encarceladas. La depuración franquista de las funcionarias de Prisiones de la Segunda República”, Cuadernos de Historia Contemporánea, 27, 2005, 271-290.

37. P. Abós Olivares (Comp.), Franquismo y magisterio. Represión y depuración de los maestros en la provincia de Teruel, Zaragoza, 2016. S. San Román, Una maestra republicana. El viejo futuro de Julia. Madrid, 2015.

38. D. Ruiz Berdún y A. Gomis, "La depuración de las matronas de Madrid tras la Guerra Civil", Dynamis, 32, 2, 2012, 439-465 y "Matronas víctimas de la guerra civil española”, Asclepio. Revista de Historia de la Medicina y de la Ciencia, 68, 2, julio-diciembre 2016, 159-177. 
algunos recientes sobre Extremadura ${ }^{39}$; los numerosos trabajos sobre Andalucía de M. Eiroa, E. Barranquero, L. Prieto, Rodríguez Padilla, Ruiz Expósito (Almería), J. M. García Márquez (Sevilla), o Pura Sánchez, que inciden no sólo en la caracterización moral que tuvo la represión sobre las mujeres, sino en otro tipo de represión de posguerra: el hambre, que las obligó a buscar estrategias de supervivencia y llevó a muchas de ellas a la cárcel, condenadas por delitos económicos como el estraperlo ${ }^{40}$.

Aspectos de la represión económica fueron abordados también en diferentes trabajos por Conxita Mir (2000-2005) para Cataluña, o Julián Casanova y Ángela Cenarro (2014) para Aragón $^{41}$, así como en otros de ámbito regional -Fuensanta Escudero para Murcia (2000); Vega Sombría para Segovia (2005); Chaves Palacios para Extremadura (2015), Julián Casanova para Aragón (2002), o los de Alicante $(2016)^{42}$, y algunos estudios generales incluidos en

39. M. Ors Montenegro, La represión de guerra y posguerra en Alicante (1936-1945), Alicante, 1995 y, con J.M. Santacreu Soler, Violencia y represión en la retaguardia, Valencia, 2006. M. Ortiz Heras, Violencia política en la II República y el primer franquismo: Albacete (1936-1950), Madrid, 1996. J. Barrado, "Mujer y derrota. La represión de las mujeres en el Teruel de la posguerra (1939)”, en AA.VV., Tiempos de silencio. Actas del IV Encuentro de Investigadores del Franquismo, Valencia, 17-19 de noviembre 1999, 7-11; C. Chaves Rodríguez, Sentenciados. La represión franquista a través de la justicia militar y los consejos de guerra en la provincia de Badajoz, Badajoz, 2015 y J. Martín Bastos, Badajoz: tierra quemada. Muertes a causa de la represión franquista, 1936-1950, Badajoz, 2015.

40. M. Eiroa, Viva Franco. Hambre, Racionamiento, Falangismo. Málaga, 1939-1942, Málaga, 1995; E. Barranquero y L. Prieto, Así sobrevivimos al hambre. Estrategias de supervivencia de las mujeres en la postguerra española, Málaga, 2003; P. Sánchez, Individuas de dudosa moral. La represión de las mujeres en Andalucía (1936-1958), Barcelona, 2009; E. Barranquero, Mujeres en la Guerra Civil y el franquismo. Violencia, silencio y memoria de los tiempos difíciles, Málaga, 2010; E. Rodríguez y J. Hidalgo, 600 mujeres. La represión franquista de la mujer almeriense (1939-1945), Almería, 2012; M. D. Ruiz Padilla, Mujeres almerienses represaliadas en la posguerra española (1939-1950), TD, Almería, 2008; J.M. García Márquez, Las víctimas de la represión militar en la provincia de Sevilla (1936-1963), Sevilla, 2012; L. Prieto, Los días de la ira. Entre Mijas y el Guadiaro, de la República a la sierra, Málaga, 2013. Un reciente estado de la cuestión, centrado en Castilla-La Mancha, pero con perspectiva comparada, puede verse en F. Alía Miranda, Ó. Bascuñán Añover, H. Vicente Rodríguez-Borlado, A.M. Villalta Luna, "Mujeres solas en la posguerra española (1939-1949). Estrategias frente al hambre y la represión”, Revista de Historiografía, 26, 2017, 213 236.

41. C. Mir Curcó, Vivir es sobrevivir. Justicia, orden y marginación en la Cataluña rural de posguerra, Lleida, 2000; C. Mir, C. Agustí y J. Gelonch (Eds.), Violencia i repressió a Catalunya durant el franquisme. Balanç historiogràfic i perspectives, Lleida, 2001 y Pobreza, marginación, delincuencia y políticas sociales bajo el franquismo, Lleida, 2005; C. Mir Curcó, "La represión sobre las mujeres en la posguerra española”, en Á. Egido, y M. Eiroa (Eds.), Los grandes olvidados. Los republicanos de izquierda en el exilio, Madrid, 2004, 205-227; J. Casanova Ruiz y Á. Cenarro Lagunas (Eds.), Pagar las culpas: la represión económica en Aragón (1936-1945), Barcelona, 2014.

42. F. Escudero Andújar, Lo cuentan como lo han vivido. República, guerra y represión en Murcia, Murcia, 2000; S. Vega Sombría, La represión franquista en la provincia de Segovia. De la esperanza a la persecución, Barcelona, 2005; J. Chaves Palacios, C. Chaves Rodríguez, C. Ibarra Barroso, J. Martín Bastos y L. Muñoz Encinar, Proyecto Recuperación de la Memoria Histórica en Extremadura. Balance de una década (2003- 
obras de conjunto ${ }^{43}$. Pero los análisis particularizados sobre la represión de las mujeres como el de Claudia Cabrero Blanco para Asturias (2006), o el de Julio Prada para Galicia (2013), son todavía escasos. En 2016 el escritor y periodista José Ramón Saiz Viadero publicó también un estudio específico sobre Cantabria ${ }^{44}$.

Se ha abordado, asimismo, el papel de las mujeres en la guerrilla, fruto de su experiencia en la resistencia contra el franquismo ${ }^{45}$. Es el caso de los trabajos de Fernanda Romeu, El silencio roto. Mujeres contra el franquismo (1994), y el de Shirley Mangini, Recuerdos de la resistencia. La voz de las mujeres de la guerra civil española (1999) ${ }^{46}$. Ya en los 2000 muchas protagonistas se animaron a publicar sus experiencias en un intento por reparar el silencio que mantuvieron durante décadas y transmitir a las generaciones su pasado traumático ${ }^{47}$. Y no hay que olvidar los testimonios del exilio, que no deja de ser otra forma de represión, donde hay que citar los de mujeres en los campos nazis y los de aquellas que actuaron con la Resistencia o que simplemente tuvieron que rehacer sus vidas en otros países comenzando desde la nada ${ }^{48}$.

Pero quedan aún muchos aspectos por desentrañar. Por ejemplo, es imposible determinar todavía el alcance de la represión subsidiaria: cuántas mujeres fueron detenidas para

2013). Investigaciones sobre la Guerra Civil y el Franquismo, Badajoz, 2015; J. Casanova Ruiz, Morir, matar, sobrevivir: la violencia en la dictadura de Franco, Barcelona, 2002; M. del Olmo Ibáñez (Coord.), Guerra Civil y memoria histórica en Alicante, Catálogo Exposición, Alicante, 2016.

43. M. Nash (Ed.), Represión, resistencias, memoria. Las mujeres bajo la dictadura franquista, Granada, 2013. M. Eiroa, "La represión, elemento central de la "Victoria", en Á. Egido y M. Núñez (Eds.), El republicanismo español. Raíces históricas y perspectivas de futuro, Madrid, 2001, 117-142 y Á. Egido, "El precio de la militancia femenina: acción política y represión”, en Á. Egido y A. Fernández Asperilla (Eds.), Ciudadanas, militantes, feministas. Mujer y compromiso politico en el siglo XX, Madrid, 2011, 47-74.

44. C. Cabrero Blanco, Mujeres contra el franquismo (Asturias 1937-1952): vida cotidiana, represión y resistencia, Oviedo, 2006; J. Prada Rodríguez (Ed.), Franquismo y represión de género en Galicia, Madrid, 2013; J. R. Saiz Viadero, Mujer, República, Guerra Civil y represión en Cantabria, Torrelavega, 2016.

45. I. Strobl, Partisanas. La mujer en la resistencia armada contra el fascismo y la ocupación alemana (1936-1945), 3a ed., Barcelona, 2015; M. Yusta Rodrigo, Madres coraje contra Franco. La Unión de Mujeres Españolas en Francia, del antifascismo a la Guerra Fría (1941-1950), Madrid, 2009 y Guerrilla y resistencia campesina. La resistencia armada contra el franquismo en Aragón (1939-1952), Zaragoza, 2003.

46. F. Romeu, El silencio roto. Mujeres contra el franquismo, $1^{\text {a }}$ ed., Llanera, 1994; S. Mangini, Recuerdos de la resistencia. La voz de las mujeres de la guerra civil española, Barcelona, 1999.

47. Á. García Madrid, Réquiem por la libertad, Madrid, 2003; R. Sender Begué, Nos quitaron la miel. Memorias de una luchadora antifranquista, Valencia, 2004; L. Quiñonero, Nosotras que perdimos la paz, Madrid, 2005; M. L. Mejías Correa, Así fue pasando el tiempo: memorias de una miliciana extremeña. Edición de M. Pulido Mendoza, Sevilla, 2006; A. R. Cañil, La mujer del maquis, 2a ed., Madrid, 2008.

48. N. Català, De la resistencia a la deportación. 50 testimonios de mujeres españolas, Barcelona, 2000; C. Cañellas y R. Torán, Dolors Piera. Maestra, politica i exiliada, Barcelona, Barcelona, 2003; O. Castellví, De las checas de Barcelona a la Alemania nazi, Barcelona, 2008; M. Núñez Targa, Destinada al crematorio. De Argelés a Ravesbrück: las vivencias de una resistente republicana española, Madrid, 2011 y El valor de la memoria, Madrid, 2016. P. Dominguez Prats, De ciudadanas a exiliadas. Un estudio sobre las republicanas españolas en México, Madrid, 2009. 
presionar a sus familiares varones huidos ${ }^{49}$, el número de años que pasaron realmente en la cárcel antes de salir con libertad vigilada o con penas reducidas, los castigos más evidentes destinados sólo a las mujeres como el rapado de pelo, la ingesta del aceite de ricino o las violaciones, difíciles de probar y cuantificar, aunque existen sobrados testimonios sobre ellos ${ }^{50}$. Que la mujer fuera considerada un botín de guerra no era nada nuevo, se había dado antes en la historia y se daría después en la Europa de la II Guerra Mundial, en uno y otro bando, como puso de manifiesto Maud Joly ${ }^{51}$, pero hay que subrayarlo porque hay suficientes pruebas de que en España también sucedió. Sin embargo, sobre este aspecto apenas tenemos una obra divulgativa publicada en $2012^{52}$.

Para reconstruir ese universo son fundamentales los testimonios, que permiten intuir, a través de los gestos y de los silencios, lo que la voz no quiere confesar. En la actualidad hay iniciativas al respecto, como el del grupo HISTAGRA de Santiago de Compostela, aunque el primero y pionero fue el documental de Fernanda Romeu $(1991)^{53}$. El boom mediático se produjo nuevamente en los 2000 con la emisión de diversos programas y documentales que incluían testimonios femeninos, algunos de ellos fundamentales para aprehender las diferentes caras de la represión ${ }^{54}$.

En consecuencia con estos estudios podríamos afirmar que, desde el punto de vista cronológico, la etapa de la inmediata posguerra va cerrándose, sobre todo en los aspectos cualitativos, aunque faltan estudios cuantitativos sobre fusilamientos, depuraciones, desaparecidas, la aplicación de la redención de penas a las mujeres, que fue más tardía y menos generosa, etc. Hay algunos trabajos sobre depuración de funcionarias, abogadas del TOP, pero son todavía escasos y es difícil hacer una valoración global por la inaccesibilidad, la inexis-

49. Sobre esto hay clara constancia, para el caso de las mujeres gallegas, en el Proyecto Voces y Nomes. En línea en: http://www.nomesevoces.net/gl/resultado/mujer-memoria-y-represion/-. Véase también: http:// www.nomesevoces.net/gl/informes/ [Consulta: 12.06.2017].

50. Recientemente M. Ors Montenegro ha recopilado los expedientes de 78 mujeres, ilicitanas o residentes en Elche, que sufrieron la violencia del franquismo. Los testimonios sobre violación pueden verse en línea en: http://www.eltaladro.es/2016/04/14/rapadas-violadas-purgadas-en-elche-me-voy-de-aqui-porque-yano-les-queda-nada-mas-que-hacerme/ [Consulta: 12.06.2017].

51. M. Joly, "Las violencias sexuadas de la guerra civil española: paradigma para una lectura cultural del conflicto", Historia Social, 61, 2008, 89-107.

52. E. González Duro, Las rapadas. El franquismo contra la mujer, Madrid, 2012. Véase también en línea: https://arcangelbedmar.com/2017/02/13/la-fotografia-de-las-mujeres-peladas-en-montilla-durante-laguerra-civil/ [Consulta: 12.06.2017].

53. F. Romeu Alfaro (Coord.), Rescatadas del olvido. Mujeres bajo el franquismo, videograbación, 1991.

54. Especialmente Del olvido a la memoria, documental producido por M. Campo Vidal y A. Sangüesa, bajo la dirección histórica de J. Montes Salguero, 2006 y J. Larrauri, Mujeres republicanas, 2010. En 2000 el Institut Universitari de Estudis de la Dona de la Universitat de València grabó El siglo XX en femenino. Ellas piden la voz y la palabra. En 2003, TV-3 de Catalunya emitió el ya referido programa sobre Els nens perduts del franquisme, "Trenta minuts", Serveis Informatius TV-3 de Catalunya, 2003. En 2004 se estrenó Mujeres en pie de guerra, un proyecto multimedia, en formato documental; en 2006 Egido y Eiroa, entre otras, participaron en otro documental titulado Mujeres y República, producido por Tesauro para el Canal Historia de Canal Satélite Digital y TVE. 
tencia de fuentes o la ausencia de sistematización de los documentos carcelarios -algunos son libros de registros de entrada, en otros casos son expedientes completos, etc.--, y porque cada investigador ha analizado la documentación más próxima y, por lo tanto, no siempre es posible ofrecer una versión coherente de conjunto. Faltaba también un estudio global que apuntara, al menos, un primer balance comparativo entre los diferentes ámbitos geográficos. Se ha intentado paliarlo en Mujer, franquismo y represión, una deuda histórica ${ }^{55}$, donde se recoge la información existente hasta la actualidad, aunque todo indica a que apenas roza la punta del iceberg. Pero sobre todo es necesario un reconocimiento generalizado para el papel de muchas mujeres que, aunque no tuvieron una participación directa en la guerra, contribuyeron a ella de muchas otras maneras y, en general, un reconocimiento para todas aquellas personas represaliadas porque habían votado al Frente Popular, a quienes durante largos años se les negó su condición de presos políticos, identificándoles sin más con la delincuencia.

\section{Aproximación a la presencia de la represión de género en la historia y la memoria digital}

Recientes estudios sobre el uso que hacen las mujeres de Internet muestran una división por género que nos remite a comportamientos estereotipados heredados del pasado siglo ${ }^{56}$. Según dichos estudios ellas utilizan más el medio online para adquirir productos y compartir información personal, mientras que los hombres se distinguen por utilizarlo fundamentalmente para cuestiones de negocios, obtener información de interés, acceder a contactos relevantes y otros recursos que ofrece la Red para mejorar el estatus profesional. En España M.L. Congosto ha demostrado que las mujeres están más presentes en Facebook y en Instagram que los hombres, mientras que éstos las superan en Twitter y Linkedin, por ejemplo ${ }^{57}$. Apenas encontramos mujeres youtubers mientras que es más fácil encontrarlas como blogger, un género de comunicación dinámico que permite realizar anotaciones o posteos de periodicidad variada y difundir todo tipo de materiales escritos y audiovisuales. En cierto modo se explica la preferencia de este formato porque se considera a los blogs como los herederos de los antiguos diarios manuscritos, un género muy común entre las mujeres para anotar sus experiencias cotidianas ${ }^{58}$.

55. Á. Egido León y J. Montes Salguero (Eds.), Mujer, franquismo y represión, una deuda histórica, Madrid, 2017.

56. I. Vermeren, “¿Quiénes son más activos en las redes sociales: los hombres o las mujeres? [estadísticas de redes sociales]”. En línea en: https://www.brandwatch.com/es/2016/03/redes-sociales-hombres-mujeres/ [Consulta: 10.2.2017].

57. Véase M.L. Congosto, "Métodos de investigación en redes sociales". Tercera sesión Seminario reflexiones teóricas y prácticas metodológicas con fuentes digitales. Universidad Carlos III de Madrid, 24 de enero de 2017. En línea en: http://uc3m.libguides.com/c.php?g=521884\&p=4033319 [Consulta: 10.2.2017].

58. S. C. Herring y J.C. Paolillo, "Gender and genre variation in weblogs", Journal of Sociolingüistics, 10, 4, 2006, 439-459. 
En este estudio se han seleccionado términos alusivos a la represión de mujeres en el franquismo -cárceles de mujeres, represión de género, fusiladas, exiliadas, deportadas, rapadas, historia social-, para realizar búsquedas en la base de datos construida con el software de Omeka en el seno del proyecto de investigación HISMEDI. La base de datos está estructurada conforme a los objetos y géneros habituales en la Red más accesibles a los ciudadanos, es decir, blogs, webs, redes sociales, boletines digitales y el canal audiovisual de Youtube. Sus contenidos proceden de los hallazgos encontrados con los recursos digitales de Google Search Advanced, buscadores especializados y la extracción de datos de hipervínculos ${ }^{59}$. La configuración de dicha base de datos en campos relativos a la identidad, los objetivos, los contenidos y aspectos relativos a la interactividad y la multimediación de cada elemento analizado, permite reunir una información bastante completa al tiempo que valorar su calidad.

Como ya mencionamos al inicio, la investigación con fuentes nativas digitales ofrece numerosos retos a la historiografía, entre otros su abordaje teórico y metodológico en el que hay que aproximarse a ciencias sociales afines como la comunicación, un terreno en el que se mueve la historia digital y, sobre todo, la historia pública digital ${ }^{60}$. Los resultados que se exponen en las siguientes páginas no pueden considerarse definitivos, aunque son una muestra bastante representativa de las evidencias digitales sobre el tema. Los datos consignados han sido confirmados con fecha 14 de marzo de 2017 y se encuentran en la exposición virtual denominada «Las mujeres como agentes y protagonistas de la Historia y la Memoria digital» que el equipo del proyecto HISMEDI va alimentando a medida que se encuentran nuevos sitios virtuales ${ }^{61}$.

De los más de 1.000 elementos analizados e incluidos en dicha base de datos, es fácilmente deducible el bajo nivel de participación y de presencia femenina en la webesfera de la historia y la memoria cuya cuantificación apenas llega al 12-15\%. Las mujeres son autoras exclusivas de un reducido número de websites y blogs y su presencia es menor en Facebook y Twitter. Suelen compartir su actividad con los hombres, mucho más dinámicos en la Red. Sin embargo son bastante participativas en documentales, grabaciones audiovisuales o reportajes emitidos por el canal de Youtube, formatos para los que prestan sus voces y testimonios con gran detalle. La brecha es mayor cuando se trata de la represión de género como objeto de estudio y disminuye cuando comprobamos la contribución de las mujeres a los estudios generales sobre la violencia del franquismo. En otras palabras, falta mucho por visualizar de la polifacética represión ejercida contra las mujeres en la inmediata posguerra, y los autores

59. Véase en línea en: http://evi.linhd.uned.es/projects/hismedi/om/ [Consulta: 11.03.2017]. La base de datos OMEKA fue creada por The Roy Rosenzweig Center of History and New Media, https://rrchnm.org/.

60. Entre la bibliografía sobre ambos terrenos mencionaremos: A. Pons, El desorden digital. Guía para historiadores y humanistas, Madrid, 2013. Del mismo autor: "Internet: un reto para el conocimiento (histórico)", Pasajes: Revista de pensamiento contemporáneo, 27, 2008, 31-42. S. Noiret, "Public History e storia pubblica nella rette", Ricerche storiche 39, 2-3, 2009, 275-327. Del mismo autor: "Historia digital e Historia pública digital", en J.A. Bresciano y T. Gil (comp.), Historiografía, giro digital y globalización. Reflexiones teóricas y prácticas investigativas, Montevideo, 2015, 41-76.

61. En línea en: http://evi.linhd.uned.es/projects/hismedi/om/exhibits/show/las-mujeres-como-agentesde-la [Consulta: 11.03.2017]. 
en su mayoría son hombres, mientras que ellas son más diligentes en las aportaciones sobre la memoria colectiva de este traumático pasado ${ }^{62}$. Una explicación de esta peculiaridad puede deberse al silencio de décadas mantenido para olvidar las humillaciones sufridas y las violaciones que ha impedido a las generaciones de hijos y nietos conocer los recuerdos de ese pasado traumático vivido por sus ascendientes incurriendo, también en el entorno digital, en el desconocimiento de esta parte de nuestro pasado en el que ellas también fueron víctimas.

La corta red de relatos sobre la represión de mujeres se centra en ámbitos como las cárceles de mujeres, su situación en las distintas prisiones de la geografía española explicada en intervenciones de historiadores y especialistas; campos de concentración y, finalmente, documentales con testimonios de las supervivientes o de sus familiares, dando paso así, a la denominada «memoria adquirida», utilizando el término que J. Aróstegui aplicó a aquel relato oral que los descendientes de los protagonistas narran al transferir el recuerdo de los sucesos $^{63}$. El término de "postmemoria« utilizado por otros autores hace referencia, igualmente, a esta emisión del pasado no vivido en primera persona pero asumido como legado familiar para las generaciones jóvenes ${ }^{64}$.

Con respecto a las cárceles contamos con algunas aportaciones que, con mayor o menor rigor, describen e interpretan este lugar de represión. Ejemplos como la web de la prisión de Les Corts, obra del historiador Fernando Hernández Holgado, no son habituales en el panorama digital ${ }^{65}$. En ella se ofrece una historia transmedia que ayuda a entender mejor la cárcel: permite la visualización del lugar, incluye testimonios de las presas, documentos de la administración carcelaria, fotografías, el contexto histórico y cronológico, así como enlaces a actividades y recursos relacionados. En definitiva una recreación bastante fiel de este pasado traumático cuya fiabilidad le hace útil para la investigación, la didáctica y la divulgación.

La cárcel de mujeres de Saturrarán se aborda desde dos lugares virtuales: en una entrada de 2007 de la web de Llum Quiñonero, y en una sección de la web de Ahaztuak 1936-

62. Véase en la sección denominada "Mujeres en Red por la Memoria", en línea en: http://evi.linhd.uned. es/projects/hismedi/om/exhibits/show/las-mujeres-como-agentes-de-la/mujeres-en-red-por-la-memoria [Consulta: 15.02. 2017].

63. J. Aróstegui (ed.) España en la memoria de tres generaciones. De la esperanza a la reparación. Madrid, 2007, 26-48. Del mismo autor: “Memorias, historias y confrontaciones. Los conceptos y el debate", en J. Cuesta Bustillo (dir.) Memorias históricas de España (siglo XX), Madrid, 2008, 20-37.

64. Véase la acepción y uso del término en L. Quílez, y J.C. Rueda (dirs), Posmemoria de la guerra civil y el franquismo. Narrativas audiovisuales y producciones culturales en el siglo XXI, Granada, 2017.

65. En línea en. http://www.presodelescorts.org/es/introducci\%C3\%B3 [Consulta: 12.02.2017] F. Hernández Holgado, "Presodelescorts.org. Las nuevas tecnologías al servicio de la memoria y la historia de la prisión de mujeres de Les Corts (Barcelona 1939-1955)", en P. Amador y R. Ruiz Franco, La otra dictadura: el régimen franquista y las mujeres, Madrid, 2007, 171-181. Del mismo autor, "Presodelescorts. org. Memoria e historia de la prisión de mujeres de Les Corts (Barcelona, 1939-1955)”, en Entelequia. Revista interdisciplinar, 7, 2008, 187-196. Igualmente, "Memoria de la prisión de mujeres de Les Corts. Un balance (2006-2014)", Ágora, 2, 2015, 89-112. 
$1997^{66}$. En el primer caso, hay un relato de ficción sobre los orígenes de las instalaciones que comenzaron siendo un gran hotel de la costa vasca para convertirse en cárcel de mujeres en 1937 con la caída del frente norte. Quiñonero toma la palabra de las asistentes a un acto homenaje el 1 de abril de 2007 organizado en Saturrarán por el gobierno vasco, y narra las vivencias de las supervivientes y sus hijas en aquella cárcel. Transmite los testimonios de algunas encarceladas y hace uso de una de las características de Internet, la interactividad, dejando abierta esta página para que los internautas dejen sus comentarios. En el segundo caso, otro homenaje realizado el 8 de marzo de 2014 sirve para divulgar lo ocurrido en esta prisión. No hay aquí ficción sino reivindicación de la memoria de estas mujeres, del número de recluidas y de sus hijos y del sufrimiento causado. Ambas websites están orientadas a la difusión y la divulgación a través de la reflexión de sus autoras sobre esta pequeña parte del universo carcelario.

Sobre la cárcel de Burgos se escribió el ensayo Yo fui presa de Franco ${ }^{67}$, cuyos autores crearon un blog con fines publicitarios en el que presentan una aproximación a la historia de las mujeres que fueron detenidas y encarceladas en esta prisión durante la Guerra Civil y la inmediata posguerra. Incluye una relación de nombres así como vivencias personales de la vida cotidiana en una ciudad de gran simbolismo para el franquismo al ser la sede del primer gobierno dirigido por Franco en tiempos bélicos. Sin embargo, lo que comenzó siendo una página publicitaria se ha convertido en un lugar donde, además de las 151 mujeres representadas en el libro, se difunden breves testimonios y microbiografías de otras que también sufrieron represión, ampliándose de este modo la transmisión de las experiencias padecidas en este penal y otros similares.

El drama que supuso el fusilamiento en agosto de 1939 de «Las Trece Rosas», cuenta igualmente con algunos lugares virtuales que rememoran su trayectoria en tiempos de la II República, su actuación en la guerra civil y su destino fatal ${ }^{68}$. La tragedia de estas mujeres de las JSU está representada con imágenes y documentos que divulgan los orígenes del cruel castigo que acabó con sus vidas. Otros lugares confirman la existencia de más casos de «trece rosas» en varias localidades de la geografía española como se muestra en el documental Sucedió en Grazalema, dedicado a revelar el asesinato de quince mujeres de la localidad o el blog de las «19 mujeres de Guillena», un caso similar ocurrido en este pueblo andaluz ${ }^{69}$.

66. En línea en: http://www.llumquinonero.es/2007/04/10/carcel-de-mujeres-de-saturraran-1937-1944/, http://www.f-osacomun.com/saturraran.htm y http://ahaztuak1936-1977.blogspot.com.es/2014/-03/saturraran-homena-je-la-mitad-del-cielo.html [Consultas: 12.02.2017]. Asimismo un post de 15 de febrero del blog Merindades en la Memoria, se hace eco de las mujeres en esta cárcel, sus carceleras y el régimen de habitabilidad en la prisión, en línea en: https://lasmerindadesenlame-moria.wordpress.com/2017/02/15/ la-carcel-de-mujeres-de-saturraran/ [Consulta: 12.02.2017].

67. F. Cardero Azobra y F. Cardero Elso, Yo fui presa de Franco, Burgos, 2015.

68. A este objetivo responden el blog en línea en: http://asociaciontrecerosas.blogspot.com.es/ y el documental https://www.youtube.com/watch?v=vTLwDRnDCr4 [Consulta: 11.03.2017].

69. Foro por la Memoria del Campo de Gibraltar (2017). “Sucedió en Grazalema”. En línea en: http:// evi.linhd.uned.es/projects/hismedi/om/items/show/765. Asociación para la Recuperación de la Memoria 
En lo que respecta a campos de concentración destaca la web de la Amical de Ravensbrück, una entidad constituida en 2009 en Barcelona para rendir homenaje a las mujeres catalanas deportadas al campo de Ravensbrück, siguiendo la iniciativa de Neus Català, la única superviviente ${ }^{70}$. En su website ofrece información sobre el campo y su organización, un censo de mujeres españolas deportadas a campos nazis así como la bibliografía y las fuentes en que está fundamentada la página. Asimismo incluye una sección de hemeroteca con información actualizada sobre campos de concentración. El censo de mujeres deportadas está contrastado con fuentes de archivo y bibliográficas, proporcionando una información rigurosa y bastante exhaustiva del perfil de las mujeres en dicho campo.

La represión de género cuenta, asimismo, con diversas grabaciones difundidas en Youtube. Un ejemplo lo encontramos en «Historia viva. Mujeres bajo el franquismo», perteneciente al Canal UNED, en el que tres especialistas responden a las preguntas de la periodista que conduce un programa sobre la represión y el encarcelamiento de mujeres en los primeros años de la dictadura. La entrevista proporciona información y opinión dirigidas a estudiantes universitarios, con un objetivo fundamentalmente didáctico y divulgativo. En este mismo ámbito académico y a través del mismo canal hemos de incluir el congreso celebrado en diciembre de 2014 sobre franquismo y represión de género, en el que se debatieron numerosos aspectos de las diversas tipologías de la violencia ejercida contra mujeres ${ }^{71}$.

Siguiendo en el entorno académico y con fines divulgativos hay distintas contribuciones, como la charla reproducida también en Youtube del historiador Iosu Chueca, que realiza un amplio análisis sobre las distintas formas de persecución económica, política y cultural a través de la legislación depuradora y coactiva del franquismo. En un estilo coloquial explica la trama planificada por el Estado para el retorno al hogar y la anulación de los derechos adquiridos en tiempos republicanos, así como las diferencias entre las múltiples formas de represión entre hombres y mujeres ${ }^{72}$. Incide en las vejaciones, los castigos y la humillación ejercida contra ellas y las cárceles donde permanecieron largos periodos de tiempo durante la Guerra Civil y la posguerra.

En Youtube se difunde, igualmente, el documental producido en 2013 por Javier Larrauri, un artista atraído por la invisibilidad de las mujeres en la historia reciente, titulado $\mathrm{La}$ luz de aquella tierra. En él se ofrecen testimonios de aquellas que, siendo niñas, tuvieron que salir a pie por la frontera entre Cataluña y Francia huyendo de las tropas franquistas que ocupaban este territorio. Con este enfoque de historia oral hay disponibles varios documentales con testimonios de las protagonistas sobre los largos años de su estancia en la cárcel. Entre

Histórica "19 Mujeres" de Guillena." En línea en: http://evi.linhd.uned.es/projects/hismedi/om/items/ show/821. [Consultas: 29.05.2017].

70. En línea en: http://www.amicalravensbruck.org/reportaje.asp?id_rep=47 [Consulta: 12.02.2017]. M. Trallero, Neus Català. La dona antifeixista a Europa, Barcelona, 2008. N. Català, Testimoni d'una supervivent, Barcelona, 2007. S. Checa y B. Bermejo, Libro memorial. Españoles deportados a los campos nazis (19401945), Madrid, 2006.

71. En línea en: https://canal.uned.es/serial/index/id/1509 [Consulta: 12.03.2017].

72. En línea en: https://www.youtube.com/watch?v=_8KilMjXfqU [Consulta: 12.02.2017]. 
otros citaremos Del olvido a la memoria, Digna Rabia, Memoria del exilio. La maternidad de Elna o Mi Manzanica, en los que se muestra la fortaleza de aquellas mujeres que sufrieron humillación, escarnio y privación de libertad por sus ideas políticas, su actuación durante la guerra civil o simplemente por su parentesco con hombres perseguidos ${ }^{73}$.

Con respecto al destino de los niños, existen diversas evidencias, como en Basque Children.org, propiedad de una asociación británica dedicada a mantener la memoria de aquellos que fueron trasladados a Gran Bretaña en 1937 tras la evacuación forzada por los bombardeos fascistas del frente norte ${ }^{74}$. O el destino desconocido de aquellos que fueron separados de sus familias y entregados en adopción a las familias del Régimen, como el grupo de la red social Facebook Todos los niños robados son también mis niños, impulsado por Soledad Luque y su familia, creado con el objetivo de averiguar dónde está uno de sus hermanos. En la actualidad se ha convertido en un referente para colectivos reunidos en torno al problema de los niños robados ${ }^{75}$.

Junto a estos contenidos específicos sobre mujeres, la represión de género está presente en la Red en lugares virtuales generales. En páginas como Todos los Nombres o Todos los Rostros, diversas microbiografías permiten conocer su trayectoria personal y su trágico destino. En la web de la Asociación para la Recuperación de la Memoria Histórica, por ejemplo, hay bastantes entradas sobre mujeres, generalmente referidas a los cuerpos encontrados en las fosas comunes, o a la celebración de conmemoraciones y homenajes en los que se rememora a aquellas que sufrieron la persecución. En la web de Justicia y Memoria de Valladolid difunden una base de datos con nombres de los represaliados, entre ellos mujeres. En esta misma línea se encuentra la página de la Federación de Foros por la Memoria que cuenta con búsquedas y propuestas de construcción de cortas biografías en las que también se están reconstruyendo las experiencias vitales femeninas. Del mismo modo en iniciativas regionales como Nomes $e$ Voces, se encuentran secciones que contienen información sobre las mujeres. Es destacable el proyecto Herri Memoria, configurado como un archivo audiovisual de historia oral abierto, que permite incorporar cualquier historia de vida recogida en el País Vasco. En su pestaña de búsquedas distinguen entre hombres y mujeres, una herramienta que facilita el análisis de la coerción por sexos practicada por el franquismo ${ }^{76}$. En la web del colectivo madrileño Memoria y Libertad, se ha incluido un listado de víctimas del franquismo en Madrid en el que se relacionan las mujeres ejecutadas en la Cárcel de Ventas a partir del libro de Hernández Holgado ${ }^{77}$. En su sección Quiénes eran aparecen registros de mujeres asesinadas entre 1939 y 1945 con datos sobre la fecha de ejecución y breves reseñas biográficas, entre ellas las

73. Javier Larráuri, tráiler en línea en: https://www.youtube.com/watch?v=8t5f5sRfJT4. Véase su clasificación y url en la exposición virtual sobre mujeres en la Red. En línea en: http://evi.linhd.uned.es/ projects/hismedi/om/exhibits/show/las-mujeres-como-agentes-de-la [Consulta: 11.03.2017].

74. En línea en: http://www.basquechildren.org/ [Consulta: 18.03.2017].

75. En línea en: https://www.facebook.com/FAMILIALUQUEDELGADO/ [Consulta: 18.03.2017].

76. Asociación Elkasko (2016)."Herri Memoria”. En línea en: http://evi.linhd.uned.es/projects/hismedi/ om/items/show/955. [Consulta: 30.05.2017].

77. En línea en: https://es.scribd.com/document/6493389/Lista-Fallecidas-Carcel-de-Ventas-FernandoHernandez-Holgado [Consulta: 11.03.2017] 
Trece Rosas. Del mismo modo en otras páginas de referencia sobre exiliados se incluye información sobre los recorridos vitales de las mujeres obligadas a marcharse del país una vez derrotado el ejército republicano. Sin embargo, en los lugares genéricos es difícil encontrarlas porque la información no está catalogada por género, una circunstancia que impide localizar y tener certeza de cuál fue la dimensión de lo ocurrido al colectivo femenino.

\section{Credibilidad, calidad y aportación de las nuevas fuentes digitales}

Una cuestión clave a la hora de abordar las fuentes digitales es comprobar su calidad y credibilidad, una evaluación obligada no sólo para usos historiográficos sino también para la consulta como internautas.

El escepticismo hacia la documentación de Internet está muy extendido, puesto que es conocida la facilidad para manipular los contenidos y las imágenes así como para difundir información sin filtros adecuados. Esta situación requiere, por tanto, de una valoración de los materiales, especialmente de los nacidos digitales. Estos últimos presentan importantes retos, puesto que sus emisores y objetivos son muy diversos y dependen, en cierta medida, de si se trata de instituciones oficiales, colectivos de diversa naturaleza o de individuos que acceden a la Red con gran desenvoltura ${ }^{78}$.

Las propuestas para el análisis, la verificación de la calidad y credibilidad de los recursos digitales no son abundantes y son obra, sobre todo, de disciplinas como la documentación y la archivística ${ }^{79}$. En general coinciden en que deben incluir indicadores de identidad como el autor/entidad emisora, la fecha de creación, la estructura y organización interna, la financiación o soporte económico y una explicación de los objetivos. A menudo esta información técnica suele aparecer en los denominados metadatos, una información descriptiva que acompaña a los recursos fiables. Otra vía para comprobar la fiabilidad y calidad de una fuente digital puede ser la verificación de preguntas relativas a la búsqueda del quién, qué, cuándo, con qué finalidad, porqué, etc., cuestiones que pretenden averiguar la autoridad de un recurso, su intencionalidad o el rigor en los contenidos. Asimismo las características de Internet como la hipertextualidad y la multimediación pueden convertirse en herramientas para acreditar la información que se difunde a través de la navegación por los enlaces que llevan a otros entornos digitales donde cotejar los datos o testimonios. La calidad de los textos, finalmente, puede verificarse a través de la comparación con la producción historiográfica

78. B. Rieder y T. Röhle: “Digital Methods: five challenges”, en D. M. Berry (eds.) Understanding Digital Humanities, Houndmills, Palgrave Macmillan, 2012, pp. 67-84. P. Groth et al: "Requirements for provenance on the Web", The International Journal of Digital Curation, 7, 1, 2012, 39-56. En línea en: http://www.ijdc. net/index.php/ijdc/article/view/203. [Consulta: 11.03.2017]. D. G. Godfrey: Methods of historical analysis in electronic media, New Jersey, 2006.

79. E. Boretti: “Valutare Internet. La valutazione di fonti di documentazione web”. En línea en: http:// www.aib.it/aib/contr/boretti1.htm. [Consulta: 11.03.2017] F. Vecchio: "La storia in rete: la valutazione delle risorse”, en Storiadelmondo, 41 (2006). En línea en: http://www.storiadelmondo.com/41/vecchio. valutazione.pdf. [Consulta: 28.05.2017]. 
offline, y la práctica de técnicas metodológicas convencionales como las consultas bibliográficas o a la documentación de archivo.

Conviene, asimismo, diferenciar las entidades públicas -archivos, universidades y centros de investigación-, de las privadas -fundaciones, colectivos, asociaciones memoriales y particulares-. En muchos casos las entidades privadas construyen sus sitios virtuales bajo el concepto de "proyectos colaborativos», es decir, aquellos que se nutren de las aportaciones de voluntarios que remiten información biográfica, jurídica o audiovisual. La mayor parte de ellas, sin embargo, no persigue elaborar un relato historiográfico, sino más bien configurar un «lugar digital de memoria» a modo de homenaje y recuerdo. Incluso algunas asumen un papel meramente divulgativo o reivindicativo de situaciones y personajes injustamente tratados por las administraciones a lo largo de décadas. Por tanto, a la hora de establecer una jerarquía cualitativa o metodológica de los recursos, han de tenerse en cuenta estos parámetros para no incurrir en errores de apreciación. En otras palabras, no es posible comparar un objeto digital realizado por historiadores como resultado de un proyecto de investigación, que otro creado por un colectivo memorial que intenta mantener la memoria de alguna víctima, aunque ambos compartan el objetivo común de visualizar la represión de género. A modo de ejemplo podríamos mencionar dos fuentes dedicadas a la cárcel de mujeres de Les Corts: la página ya referida «Memoria Prisión de Mujeres de Les Corts. Barcelona, 1939-1955»- obra de un historiador-, de excelente calidad y credibilidad para la reconstrucción histórica; y el grupo de Facebook «Futur Monument Presó de Dones de les Corts. Barcelona. Gènere i Memòria»-obra de un colectivo- destinado a impulsar la construcción de un monumento a dicha cárcel y, por tanto, en el ámbito de la memoria colectiva ${ }^{80}$. En el primer caso estaríamos ante un elemento con función historiográfica mientras que en el segundo estaríamos ante un elemento con función divulgativa y reivindicativa y, en consecuencia, factible de utilización en los estudios sobre posmemoria y memoria colectiva.

En lo que respecta a la represión de mujeres, objeto de estudio de este texto, se podría establecer una categorización múltiple: por un lado las fuentes digitales que pueden contribuir a la construcción histórica de los acontecimientos, como las ya citadas de las cárceles de Les Corts y Burgos, el documental Tras las rejas franquistas sobre la cárcel de Segovia, la web del campo de concentración de Ravensbrück, y las diversas intervenciones de especialistas sobre la materia. Por otro lado un conjunto de aportaciones bien documentadas obra de colectivos que muestran la historia de las represaliadas y reivindican su sitio en la historia. Es el caso, entre otros, de la página web «Parque de la Memoria», sobre el llamado "pueblo de las viudas», el documental Sucedió en Grazalema -narración del fusilamiento de quince vecinas de la localidad-, el blog «Asociación para la Recuperación de la Memoria Histórica «19 Mujeres» de Guillena»-de temática similar-, el documental Prohibido recor-

80. F. Hernández Holgado, “Memoria Prisión de Mujeres de Les Corts. Barcelona, 1939-1955”. En línea en: http://evi.linhd.uned.es/projects/hismedi/om/items/show/190 [Consulta: 29.05.2017]. Colectivo Plataforma para el Futuro Monumento de la Cárcel de Mujeres de Les Corts (2010). "Futur Monument Presó de Dones de les Corts. Barcelona. Gènere i Memòria”. En línea en: http://evi.linhd.uned.es/projects/ hismedi/om/items/show/834. [Consulta: 29.05.2017]. 
dar. Cárcel de Saturrarán, o los lugares genéricos dedicados a la represión que incluyen a las mujeres, como las páginas de Todos los Nombres, Nomes e Voces, Todos los Rostros, Herri Memoria, etc. ${ }^{81}$. En tercer lugar la contribución oral de mujeres que prestan su testimonio sobre la experiencia vital en los centros de represión ${ }^{82}$. En esta categoría, que podría situarse bajo el ámbito de una historia oral digital, resulta ineludible contrastar su palabra con documentación archivística y bibliográfica, un proceso del que no está exento la práctica de la historia oral convencional. Finalmente figurarían los sitios virtuales y las redes sociales orientadas al homenaje, la reivindicación y la búsqueda de verdad, justicia y reparación. En este grupo se podría señalar a la Federación de Foros por la Memoria, la Asociación para la Recuperación de la Memoria Histórica o blogs como «13 Rosas Asturias», agentes relevantes de la memoria colectiva del fenómeno represor.

La selección de estos materiales para su utilización depende de los objetivos planteados en cada investigación. Cada uno de ellos aporta un enfoque, una visión y una perspectiva diferente de la represión de mujeres en las plataformas sociales: desde el oficial de las instituciones públicas, al historiográfico, el memorial o el reivindicativo de entidades privadas. En cualquier caso suscitan interrogantes y líneas de investigación novedosas sobre la visibilidad de las mujeres, la construcción de una historia «desde abajo» basándose en las microbiografías y los testimonios orales existentes en la Red, la revelación de nuevos datos sobre el tema utilizando las fuentes digitales construidas en pequeñas localidades y provincias, etc.

\section{Algunas reflexiones}

Los hallazgos provisionales sobre la presencia y representación de la represión de género permiten algunas conclusiones iniciales. En primer lugar, es evidente que hay una brecha de género en la representación de la Historia y la Memoria en el entorno digital. La brecha se comprueba en los autores de estos formatos digitales, en los que prevalecen los hombres y en los que hay una baja participación femenina como autoras exclusivas. También hay una importante brecha en los contenidos, cuyos mensajes y relatos se refieren mayoritariamente a los hombres. Ciertamente la producción historiográfica ha demostrado que la represión contra ellos fue cuantitativamente mayor, pero hay ya muchas investigaciones -como se ha expuesto en la primera parte de este texto- que muestran claramente la espe-

81. Asociación Pueblo de las Viudas de Sartaguda / Alargunen Herriko Elkartea (2009). "Parque de la Memoria”. En línea en: http://evi.linhd.uned.es/projects/hismedi/om/items/show/658. Foro por la Memoria del Campo de Gibraltar (2017). "Sucedió en Grazalema”. En línea en: http://evi.linhd.uned.es/ projects/hismedi/om/items/show/765. Asociación para la Recuperación de la Memoria Histórica "19 Mujeres” de Guillena“. En línea en: http://hismedi.evilinhd.com/om/items/show/821. Darrai DocuVideos (2012). “Prohibido recordar. Cárcel de Saturrarán”. En línea en: http://evi.linhd.uned.es/projects/hismedi/ om/items/show/945. [Consultas: 29.05.2017].

82. En línea en: http://evi.linhd.uned.es/projects/hismedi/om/exhibits/show/las-mujeres-como-agentesde-la/testimonios-audiovisuales-de-1 [Consulta: 29.05.2017]. 
cificidad de la aplicada a las mujeres que está poco visible en la Red, con alguna excepción ya indicada. En otras palabras, hay una escasa constancia de la represión de género en el universo digital y esta carencia refrenda la invisibilidad que tradicionalmente han tenido las mujeres en la Historia. Cierto es que en casi todas las páginas de la represión genérica cuentan con herramientas de búsqueda para encontrar las relaciones de represaliados y en ellas están presentes las mujeres, pero apenas hay lugares virtuales centrados en la explicación de cuál fue su historia y su experiencia.

En segundo lugar estas fuentes transmedia nos remiten al conocimiento de un pasado distinto y esto supone un reto para los historiadores. No podemos soslayar la existencia de entornos digitales donde se ofrecen testimonios de los acontecimientos, fuentes orales, visuales, auditivas, etc., porque tenemos la oportunidad de comprobar con nuevos elementos de juicio y análisis qué fue lo ocurrido. En ellos nos encontramos la voz y el sonido, la estética de las mujeres de la época -que ahora es posible conocer-. Estas nuevas fuentes y perspectivas darán como resultado un incremento de la historia social y la construida «desde abajo».

En tercer lugar, si las investigaciones de la historiografía convencional sobre la represión de mujeres han requerido la utilización de enfoques inéditos y la búsqueda de originales fuentes documentales que extraigan del olvido su historia, también en la Web 2.0 hay que destinar espacios y configuraciones novedosos para el estudio del fenómeno represor de género que muestre las características del mismo, desde el perfil biográfico de las víctimas hasta su trayectoria política, profesional o doméstica, sus teóricos delitos y sus múltiples memorias y reacciones ante la hostilidad mostrada por el franquismo hacia estas mujeres transgresoras de su moral.

Las características de Internet relativas a la posibilidad de incluir elementos multimediáticos -fotografías, voz, sonidos, documentos textuales-, hipertextos -con enlaces a otros lugares como archivos digitalizados, por ejemplo, para ampliar la información o contrastarla-, o la interactuación - una herramienta que permite a los usuarios enviar datos para construir microbiografías o aportar información-, habilitan la multiplicación del conocimiento sobre las mujeres en nuestra historia. Hay posibilidad de hacerlas visibles con la difusión de su imagen, su voz, su estética, sus sentimientos y recuerdos y, en consecuencia, de construir un pasado más próximo al rigor deseado por la comunidad académica y más empático con los hipotéticos lectores del presente. 